\title{
Can non-functional adrenal incidentaloma be ranked among cardiovascular risk factors?
}

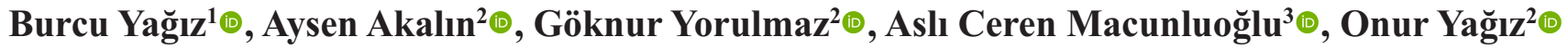 \\ ${ }^{1}$ Department of Internal Medicine, Eskişehir Osmangazi University Faculty of Medicine, Eskişehir, Turkey; ${ }^{2}$ Department of \\ Endocrinology and Metabolism, Eskişehir Osmangazi University Faculty of Medicine, Eskişehir, Turkey; ${ }^{3}$ Department of Biostatistics, \\ Bursa Uludag University Faculty of Medicine, Bursa, Turkey
}

\begin{abstract}
Objectives: We aimed to evaluate the potential association of a nonfunctional adrenal incidentaloma (NFAI) with cardiovascular risk factors.

Methods: Forty-three patients over the age of 40 found to have NFAI and 28 healthy controls were included in this prospective study. The control group was selected from individuals who were similar in age and gender. Glucose, insulin, c-peptide, lipid profile, erythrocyte sedimentation rate, high sensitivity c-reactive protein, fibrinogen and 25-hydroxy cholecalciferol and carotid artery intima-media thickness (CIMT) were measured in both groups.
\end{abstract}

Results: Waist circumference, erythrocyte sedimentation rate, triglyceride and CIMT values were found higher in the patient group ( $p=0.002, p<0.001, p=0.001, p=0.024$, respectively). It was observed that $10(23.2 \%)$ of the patients had no suppression with $1 \mathrm{mg}$ dexamethasone but suppression was provided with $2 \mathrm{mg}$ dexamethasone for 2 days, and all of these patients with 'possible autonomous cortisol secretion' had at least one comorbidity. While there was no significant difference between the groups in terms of the presence of comorbidity, a significant difference was found in terms of diabetes mellitus $(90 \%$ of the patients with autonomous cortisol secretion, $24.2 \%$ of those who were suppressed with $1 \mathrm{mg}$ dexamethasone had diabetes mellitus; $p<0.001$; Chi-square test).

Conclusions: Higher waist circumference, erythrocyte sedimentation rate, triglyceride and CIMT values in our patients with NFAI and increased diabetes mellitus frequency in patients with autonomous cortisol secretion suggest that NFAI may be one of the cardiovascular risk factors.

Keywords: Autonomous cortisol secretion, cardiovascular risk, carotid intima-media thickness, non-functional adrenal incidentaloma

$\mathrm{T}$ he incidence of adrenal incidentalomas (AI) increases day by day. The most important reason for this is the development and use of high-tech diagnostic methods [1]. The basic approach in a patient in whom an adrenal mass is detected by coincidence is to differentiate benign/malignant mass and evaluate its hormonal status.

The presence of AI is thought to be associated with various cardiovascular disease (CVD) risk factors [2, 3]. Some studies have shown that the frequency of obesity, hypertension (HT), glucose intolerance, diabetes mellitus (DM), hyperuricemia, and hyperlipi- 
demia (HPL) is increased in patients with AI [2, 4-8]. Although these pathologies are more common in subclinical Cushing's syndrome, it has been noticed that they are also common in non-functional adrenal masses, and therefore it has been suggested that the presence of AI may be the cause of the metabolic syndrome $[2,5,6]$. It is thought that the presence of increased cardiovascular and metabolic risk factors may be due to the increased cortisol production from these masses, albeit slightly [9]. However, unluckily, this moderate cortisol elevation cannot be demonstrated with sufficient sensitivity and specificity [4, 10-12]. Therefore, it is still unclear whether non-functional adrenal masses increase risk of the CVD and whether there is an autonomous cortisol function in this type of adrenal masses.

study aimed to demonstrate increased cardiovascular risk factors and endothelial dysfunction by studying inflammation markers, lipid profile, homocysteine, 25-hydroxy cholecalciferol (25-OH-D3) parameters that play a role in atherosclerosis in patients with nonfunctional adrenal incidentaloma (NFAI) and by measuring carotid artery intima-media thickness (CIMT), which is an indicator of subclinical atherosclerosis and to evaluate whether the presence of NFAI could have an impact on cardiovascular and metabolic parameters.

\section{METHODS}

The study was conducted prospectively in Eskişehir Osmangazi University Faculty of Medicine, Department of Endocrinology and Metabolic Diseases. Before the study, all patients were given an informed consent form containing the study's details, and the patients whose consents were obtained were included in the study. The study was approved with the decision of Eskişehir Osmangazi University Ethics Committee dated 27.01.2012 and numbered 14 .

Forty-three patients over the age of 40 admitted due to incidental detection of an adrenal mass during imaging studies performed for different reasons were included in our study. The control group consisted of 14 healthy controls similar in age and gender, with a body mass index (BMI) between 19-25 and 14 obese controls with a BMI of $\geq 30$. Both control groups were selected from individuals without adrenal mass and metabolic syndrome components such as coronary artery disease (CAD), DM, HT, and HPL.

Patients who were found to have incidentaloma were questioned about diseases such as DM, HT, HPL, CAD, and medication use history. General physical examinations and examinations regarding hypercortisolism's phenotypic features were performed, and systolic and diastolic blood pressures were measured. Height, weight, and waist circumference of all patients were recorded, and BMI was calculated using the formula weight $/$ height $^{2}\left(\mathrm{~kg} / \mathrm{m}^{2}\right)$.

After 10 hours of fasting, the patients' morning glucose and insulin levels were measured, and insulin resistance was calculated using the Homeostasis Model Assessment (HOMA) formula. ESR, high sensitivity c-reactive protein (hsCRP), and fibrinogen levels as markers of inflammation and c-peptide and lipid profile [low-density lipoprotein cholesterol (LDL), high-density lipoprotein cholesterol (HDL), triglyceride (TG)] as metabolic parameters were studied from blood samples taken during fasting. Serum samples were obtained after fasting for homocysteine measurement.

The patients were divided into two groups according to the 25-OH-D3 vitamin level (20 was taken as a cut-off) and CVD risk factors were compared between these two groups. Correlation analysis of 25-OH-D3 deficiency with other risk factors for CVD was also performed.

To determine the hormone activity of the adrenal mass detected before the study, adrenocorticotropic hormone (ACTH) and morning cortisol from the blood sample taken at 08:30 in the morning at the latest were measured. Night cortisol was taken at 23:00 to comply with diurnal rhythm. Urine-free cortisol was studied in the 24-hour urine sample. An overnight $1 \mathrm{mg}$ dexamethasone suppression test (DST) was applied to the patients, and cortisol was studied at 08:30 in the morning at the latest from the patient who was given $1 \mathrm{mg}$ DXM at 23:00. Patients who were not suppressed with $1 \mathrm{mg}$ DXM were tested with a 2-day low dose. Suppression was considered sufficient if morning cortisol levels were less than $1.8 \mu / \mathrm{dL}$. However post-dexamethasone serum cortisol levels between 1.9-5.0 $\mu \mathrm{g} / \mathrm{dL}$ should be evaluated as evidence of 'possible autonomous cortisol secretion (ACS)' and post dexam- 
ethasone cortisol levels $5.0 \mu \mathrm{g} / \mathrm{dL}$ should be considered as evidence of 'ACS' [13]. The values of Vanillylmandelic acid (VMA), metanephrine-normetanephrine, adrenaline-noradrenaline, serotonin, and dopamine were studied in 24hour urine collected in storage containing $25 \%$ hydrochloric acid after a special diet devoid of phenolic acid-containing foods and beverages for five days. Biochemically proven non-functional patients were included in the study.

Adenoma and non-adenoma differentiation were made with dynamic adrenal computed tomography (CT) of adrenal masses detected in various imaging methods performed in our patients for different reasons. The size, localization, density, smoothness of the borders and the presence of invasion were determined, so only those considered adenomas radiologically were included in the study.

CIMT measurement was performed with the help of carotid doppler ultrasonography (USG) and was measured by the same person using the Toshiba Doppler USG device. Ideally, measurements were taken from the common carotid artery, approximately $1 \mathrm{~cm}$ before the carotid separation, at the artery's thickest part.

Glucose, insulin, C-peptide, erythrocyte sedimentation rate (ESR), high sensitivity c-reactive protein (hsCRP), fibrinogen, homocysteine, lipid profile, and 25-OH-D3 vitamin levels of the control group were also studied, and insulin resistance was calculated. Height, weight, and waist circumference were recorded, BMI was calculated. CIMT measurement was made.

\section{Statistical Analysis}

The compatibility of the parameters to normal distribution was examined using the Shapiro Wilk test. Continuous parameters were expressed with median (minimum: maximum) and mean \pm standard deviation values, and categorical variables with $\mathrm{n}(\%)$. Independent sample t-test or Mann Whitney $U$ test was used to compare two groups according to the normality test results. When the number of groups was more than two, the ANOVA test was used for comparisons and Tukey HSD test for the subgroup analysis, or Kruskal Wallis test was used and Dunn-Bonferroni approach for subgroup analysis. Chi-square test, Fisher's
Exact test, or Fisher-Freeman-Halton test were performed for intergroup comparisons of categorical parameters. Relationships between continuous parameters were analyzed using correlation analysis, and the Pearson correlation coefficient or Spearman correlation coefficient was calculated according to the result of the normality test. Multiple linear regression analysis was performed to estimate CIMT. SPSS (IBM Corp. Released 2012. IBM SPSS Statistics for Windows, Version 21.0. Armonk, NY: IBM Corp.) program was used for statistical analysis and a p-value of $p<0.05$ was considered statistically significant.

\section{RESULTS}

A total of forty-three patients, thirty $(69.77 \%)$ females and thirteen (30.23\%) males over the age of 40 were included in our study (Table 1). It was observed that the mean age was 53 years (40-67 years) in the patient group and 49 years (44-69 years) in the control group ( $p>0.05$, Mann Whitney U test).

When the patient and the control group were compared a statistically significant difference was found between the patient and the control group in terms of waist circumference, ESR, TG and CIMT measurements. Waist circumference, ESR, TG and CIMT values were higher in the patient group compared to the control group ( $p=0.002, p<0.001, p=0.001, p=$ 0.024 , respectively). BMI, glucose, insülin, HOMA, hsCRP, fibrinogen, homocysteine and LDL levels were higher but statistically not significant in the patients than the control group.

Then the control group was divided according to BMI levels as normal BMI and obese groups. The patients' median ESR values were found to be significantly higher than the control group with normal BMI $(p<0.001)$. The patients' median TG values were found to be higher than both the normal weight and obese groups $(p=0.004)$. While there was a significant difference between the patient and the control groups in terms of CIMT, no difference was found when the three groups were compared.

Ten $(23.2 \%)$ of the patients had no suppression with $1 \mathrm{mg}$ dexamethasone (DXM) but suppression was provided with $2 \mathrm{mg}$ DXM for 2 days, and all of these patients with 'possible ACS' had at least one co- 
Table 1. Comparison of patients and control groups in terms of parameters

\begin{tabular}{|c|c|c|c|c|}
\hline & $\begin{array}{c}\text { Patient } \\
\text { Group }(n=43)\end{array}$ & $\begin{array}{c}\text { Normal BMI } \\
\text { Group }(n=14)\end{array}$ & $\begin{array}{c}\text { Obese Group } \\
(\mathrm{n}=14)\end{array}$ & $p$ value \\
\hline \multicolumn{5}{|l|}{ Gender } \\
\hline Female & $30(69.77 \%)$ & $6(42.86 \%)$ & $11(78.57 \%)$ & $0.111^{\mathrm{c}}$ \\
\hline Male & $13(30.23 \%)$ & $8(57.14 \%)$ & $3(21.43 \%)$ & \\
\hline Age & $53(40-67)$ & $49(44-69)$ & $50(44-68)$ & $0.723^{\mathrm{a}}$ \\
\hline Body mass index $\left(\mathrm{kg} / \mathrm{m}^{2}\right)^{*}$ & $31.17 \pm 6.14$ & $25.18(16.90-28.20)$ & $31.70(30-41.10)$ & $<0.001^{\mathrm{a}}$ \\
\hline Waist circumference $(\mathrm{cm})^{\epsilon}$ & $103.84 \pm 14.34$ & $85.93 \pm 11.63$ & $100.07 \pm 8.86$ & $<0.001^{\mathrm{b}}$ \\
\hline Glucose (mg/dL) & $93(63-363)$ & $91(79-123)$ & $88.50(81-100)$ & $0.486^{\mathrm{a}}$ \\
\hline Insulin (mlU/L) & $9.95(0.20-96)$ & $7.53(3.57-20.60)$ & $9.63(6.85-19.20)$ & $0.441^{\mathrm{a}}$ \\
\hline HOMA & $2.25(0.13-17.70)$ & $1.68(0.80-6.25)$ & $1.98(1.40-4.59)$ & $0.393^{\mathrm{a}}$ \\
\hline $\operatorname{ESR}(\mathrm{mm} / \mathrm{h})^{¥}$ & $21(1-59)$ & $5(2-17)$ & $10.50(3-36)$ & $<\mathbf{0 . 0 0 1}^{\mathrm{a}}$ \\
\hline hsCRP (mg/L) & $3.40(0.40-15.50)$ & $3.08(0.50-3.30)$ & $3.19(1.30-20.10)$ & $0.103^{\mathrm{a}}$ \\
\hline Fibrinogen (mg/dL) & $355.65 \pm 92.84$ & $323.43 \pm 66.77$ & $339.64 \pm 75.45$ & $0.451^{\mathrm{b}}$ \\
\hline Homocysteine (mcmol/L) & $13.30(5.80-50)$ & $14.10(7.15-22.30)$ & $11.45(9.15-16.60)$ & $0.247^{\mathrm{a}}$ \\
\hline $\mathrm{LDL}(\mathrm{mg} / \mathrm{dL})$ & $128.07 \pm 29.99$ & $120.36 \pm 26.91$ & $121.57 \pm 28.20$ & $0.601^{b}$ \\
\hline HDL (mg/dL) & $45(29-89)$ & $51(31-77)$ & $55.50(29-75)$ & $0.152^{\mathrm{a}}$ \\
\hline $\mathrm{TG}(\mathrm{mg} / \mathrm{dL})^{\&}$ & $132(62-259)$ & $89(39-194)$ & $97.58(43-248)$ & $0.004^{\mathrm{a}}$ \\
\hline 25-OH-D3 (ng/mL) & $12.50(3.96-39)$ & $16.80(9.33-29.63)$ & $11.09(4.90-6.30)$ & $0.514^{\mathrm{a}}$ \\
\hline CIMT (mm) & $0.70 \pm 0.24$ & $0.30(0.80-0.55)$ & $0.55(0.30-0.80)$ & $0.105^{\mathrm{a}}$ \\
\hline
\end{tabular}

Data are expressed as $\mathrm{n}(\%)$, median (minimum: maximum) and mean \pm standard deviation. HOMA $=$ Homeostasis Model Assessment, ESR = Erythrocyte sedimentation, hsCRP = high sensitivity c-reactive protein, LDL = low-density lipoprotein cholesterol, HDL = high-density lipoprotein cholesterol, TG = triglyceride, 25-OH-D3 = 25-hydroxy cholecalciferol, CIMT $=$ carotid artery intima-media thickness.

${ }^{\mathrm{a}}$ Kruskal-Wallis test, ${ }^{\mathrm{b}}$ ANOVA test, ${ }^{\mathrm{c}}$ Fisher-Freeman Halton test, $*$ The median BMI values of the normal weight group were found to be lower than the patient and obese groups $(p<0.001$ and $p<0.001$, respectively). No statistically significant difference was found between the patient group and the obese group $(p=0.689)$. ${ }^{€}$ The mean waist circumference values of the normal weight group were lower than the patient and obese groups $\left(p<0.001\right.$ and $\mathrm{p}<0.016$, respectively). ${ }^{\ddagger}$ Median ESR values of the patient group were found to be higher than the normal weight group $(p<0.001)$. No statistically significant difference was found between the patient group with the obese group, and the normal weight group with the obese group ( $p=0.202$ and $p=0.104$, respectively). ${ }^{\&}$ Median TG values of the patient group were found to be higher than the normal weight and obese group ( $p=0.015$ and $p=0.049$, respectively). No statistically significant difference was found in TG values between the normal weight group and the obese group $(p>0.05)$.

morbidity (DM, HT, HPL, CVD). Of the 33 patients suppressed with $1 \mathrm{mg}$ of DXM, $72.3 \%$ had comorbidity. While there was no significant difference between the groups in terms of the presence of comorbidity, a significant difference was found in terms of DM when comorbidities were examined one by one $(90 \%$ of the patients with ACS had DM, 24.2\% of those who were suppressed with $1 \mathrm{mg}$ DXM had DM; $p<0.001$; Chisquare test).

Then these ten patients with ACS were removed and adrenal incidentaloma patients with suppressible cortisol secretion with $1 \mathrm{mg}$ DXM were compared with control groups (Table-2). The patient group had more DM, HT, HPL, and macrovascular diseases than the control group ( $p=0.005, p<0.001, p=0.01$ and $p=0.017$, respectively). In the group of patients, CIMT was also significantly higher $(p<0.05)$.

In the patient group, no significant relationship was found between right and left CIMT values and ACTH, morning and night cortisol, cortisol after DXM suppression, urinary cortisol, and adenoma size $(p>0.05)$. In the multiple linear regression analysis, 
Table 2. Comparison of patients with suppressible cortisol secretion with 1 mg DXM and control groups in terms of parameters

\begin{tabular}{|c|c|c|c|}
\hline & $\begin{array}{c}\text { Patient Group* } \\
\quad(n=33)\end{array}$ & $\begin{array}{c}\text { Control Group } \\
(\mathrm{n}=28)\end{array}$ & $p$ value \\
\hline Gender & & & $0.629^{\infty}$ \\
\hline Female & $22(66.6 \%)$ & $17(60.7 \%)$ & \\
\hline Male & $11(33.3 \%)$ & $11(39.2 \%)$ & \\
\hline Age (years) & $52.24 \pm 8.93$ & $51.42 \pm 7.44$ & $0.704^{\alpha}$ \\
\hline Weight (kg) & $80.97 \pm 16.32$ & $75.53 \pm 13.68$ & $0.168^{\alpha}$ \\
\hline Body mass index* $\left(\mathrm{kg} / \mathrm{m}^{2}\right)$ & $30.78 \pm 6.34$ & $28.73 \pm 5.34$ & $0.183^{\alpha}$ \\
\hline Waist circumference $(\mathrm{cm})$ & $103.78 \pm 15.94$ & $93.0 \pm 12.43$ & $0.005^{\alpha}$ \\
\hline Diabetes mellitus & $8(24.2 \%)$ & 0 & $\mathbf{0 . 0 0 5}^{\infty}$ \\
\hline Hypertension & $16(48.4 \%)$ & 0 & $<0.001^{\infty}$ \\
\hline Hyperlipidemia & $7(21.2 \%)$ & 0 & $0.01^{\infty}$ \\
\hline Macrovascular disease & $6(18.1 \%)$ & 0 & $0.017^{\infty}$ \\
\hline Glucose $(\mathrm{mg} / \mathrm{dL})$ & $104.51 \pm 52.42$ & $91.14 \pm 9.22$ & $0.159^{\alpha}$ \\
\hline Insulin (mlU/L) & $14.01 \pm 17.61$ & $9.90 \pm 4.55$ & $0.205^{\alpha}$ \\
\hline HOMA & $3.25 \pm 3.5$ & $2.31 \pm 1.29$ & $0.161^{\alpha}$ \\
\hline $\operatorname{ESR}(\mathrm{mm} / \mathrm{h})$ & $18.75 \pm 10$ & $12.76 \pm 8.58$ & $0.002^{\alpha}$ \\
\hline Fibrinogen (mg/dL) & $351.06 \pm 82.10$ & $331.53 \pm 70.39$ & $0.328^{\alpha}$ \\
\hline Homocysteine $(\mathrm{mcmol} / \mathrm{L})$ & $14.36 \pm 7.79$ & $12.99 \pm 3.22$ & $0.363^{\alpha}$ \\
\hline $\mathrm{LDL}(\mathrm{mg} / \mathrm{dL})$ & $130.09 \pm 30.27$ & $120.96 \pm 27.05$ & $0.223^{\alpha}$ \\
\hline HDL (mg/dL) & $47.45 \pm 13.54$ & $52.50 \pm 12.77$ & $0.142^{\alpha}$ \\
\hline $\mathrm{TG}(\mathrm{mg} / \mathrm{dL})$ & $141.27 \pm 52.84$ & $102.46 \pm 52.93$ & $0.006^{\alpha}$ \\
\hline 25-OH-D3 (ng/mL) & $15.92 \pm 9.31$ & $17.92 \pm 16.89$ & $0.561^{\alpha}$ \\
\hline CIMT (mm) & $0.68 \pm 0.21$ & $0.59 \pm 0.15$ & $0.05^{\alpha}$ \\
\hline
\end{tabular}

*10 patients who were not suppressed with $1 \mathrm{mg}$ dxm were removed. Data are expressed as $\mathrm{n}(\%)$, median (minimummaximum) and mean \pm standard deviation. DXM $=$ dexamethasone, HOMA $=$ Homeostasis Model Assessment, ESR $=$ Erythrocyte sedimentation, LDL = low-density lipoprotein cholesterol, HDL $=$ high-density lipoprotein cholesterol, TG $=$ triglyceride, 25-OH-D3 = 25-hydroxy cholecalciferol, CIMT = carotid artery intima-media thickness.

${ }^{\alpha}$ Independent sample t-test, ${ }^{\infty} \mathrm{Chi}$-square test

it was found that the only variable that showed a positive correlation with CIMT independently was age.

\section{DISCUSSION}

Adrenal masses that are clinically asymptomatic and detected incidentally in diagnostic tests for unrelated diseases are called AI [14-16]. Developments in imaging methods have resulted in an increasing number of detections of AI [15]. Because of the increasing incidence of AI with age [17], it is crucial to determine whether AI is among the risk factors in this group, in whom the risk of CVD increases.

$\mathrm{AI}$ is mostly considered as benign, asymptomatic lesions. However, recent studies have shown that abnormalities in the ACS and hypothalamic-pituitaryadrenal axis are more common than thought. The prevalence of ACS, which is the most common hormonal change in AI, varies due to differences in diagnostic tests and different cut-offs in studies [18]. Bulow et al. [19] reported a prevalence of $2 \%$, Libe et 
al. [20] 18\%, and Terzolo et al. [21] 5-20\% (review of different series) [22,23]. The possible ACS diagnosis was based on a $1 \mathrm{mg}$ DXM in our study, and the rate was found to be $23.2 \%$.

ESR is a nonspecific inflammation marker and is one of the known risk factors for CVD. In our study, the ESR value was higher in patients than in the control group $(p<0.001)$. However, there was no difference between the patients and the obese group and between the normal weight and obese groups. In a study conducted by López-Bermejo et al. [24], it was found that ESR is independently associated with obesity. Although obesity is associated with increased ESR, the lack of difference between obese and normal control groups in our study suggests the presence of subclinical inflammation in patients with AI.

It was reported that increased CIMT is an indicator of atherosclerosis and correlates with myocardial infarction, stroke, and peripheral artery diseases [25-28]. The first finding encountered in atherosclerosis is an increase in intima-media thickness [25, 29]. Similar to various previous studies [30-32] in our study, CIMT was statistically higher in patients with AI than in the control group.

Type 2 DM is comorbidity associated with ACS, and it was present in $90 \%$ of our patients with ACS. Patients with ACS have a higher prevalence of Type 2 DM estimated in the range of $20-75 \%$, depending on the diagnostic criteria used [22]. Also, ACS prevalence varies between $0-9.4 \%$ in type 2 DM [33-35], and the risk increases in those with poor metabolic control, microvascular complications, obesity, and HT [36]. Therefore, it is unclear whether AI increases the risk of metabolic syndrome or whether this type of adrenal tumor is more common in people with cardiometabolic risk factors such as type $2 \mathrm{DM}$.

In our study, the patient group with NFAI had more DM, HT, HPL, and macrovascular diseases than the control group. The presence of increased cardiovascular and metabolic risk factors is thought to be due to slightly increased cortisol production from these masses [9]. Unfortunately, due to a lack of sensitivity and specificity, this mild cortisol elevation cannot be demonstrated [9-12].

\section{Limitations}

Our main limitation is that we do not have a group that has AI but no DM, HT, CAD, PAD. Although the rate of other diseases other than HT is low and patients with concomitant diseases under control were selected, this situation may appear like a confounding factor. However, the fact that our study was conducted prospectively is a significant advantage as well as being its limitation.

\section{CONCLUSION}

In this study, we aimed to evaluate the relationship between cardiovascular diseases, one of the most important causes of death today, and AI. Increased ESR and increased CIMT were significant risk factors for atherosclerosis as well as traditional risk factors, and DM was more common in the ACS group. It was thought that subclinical inflammation and insidious cortisol autonomy, which is thought to have metabolic effects, may cause this situation.

\section{Authors' Contribution}

Study Conception: BY, AA; Study Design: BY, AA; Supervision: AA, GY; Funding: N/A; Materials: N/A; Data Collection and/or Processing: BY, OY; Statistical Analysis and/or Data Interpretation: GY, OY, ACM; Literature Review: BY, OY, GY; Manuscript Preparation: BY and Critical Review: AA, GY.

\section{Conflict of interest}

The authors disclosed no conflict of interest during the preparation or publication of this manuscript.

\section{Financing}

The authors disclosed that they did not receive any grant during conduction or writing of this study.

\section{REFERENCES}

1. Prager G, Peer GH, Passler C, Kaczirek K, Schindl M, Scheuba $\mathrm{C}$, et al. Surgical strategy in adrenal masses. Eur J Radiol 2002;41:70-7.

2. Terzolo M, Pia A, Alì A, Osella G, Reimondo G, Bovio S, et al. Adrenal incidentaloma: a new cause of the metabolic syndrome? J Clin Endocrinol Metab 2002;87:998-1003.

3. Fernández-Real JM, Engel WR, Simó R, Salinas I, Webb SM. Study of glucose tolerance in consecutive patients harbouring incidental adrenal tumours. Clin Endocrinol (Oxf) 1998;49:53-61. 4. Rossi R, Tauchmanova L, Lucano A, Di Martino M, Battista C, Del Viscovo L, et al. Subclinical Cushing's syndrome in pa- 
tients with adrenal incidentaloma: clinical and biochemical features. J Clin Endocrinol Metab 2000;85:1440-8.

5. Di Dalmazi G, Vicennati V, Rinaldi E, Morselli-Labate AM, Giampalma E, Mosconi C, et al. Progressively increased patterns of subclinical cortisol hypersecretion in adrenal incidentalomas differently predict major metabolic and cardiovascular outcomes: a large cross-sectional study. Eur J Endocrinol 2012;166:669-77. 6. Di Dalmazi G, Vicennati V, Garelli S, Casadio E, Rinaldi E, Giampalma E, et al. Cardiovascular events and mortality in patients with adrenal incidentalomas that are either non-secreting or associated with intermediate phenotype or subclinical Cushing's syndrome: a 15-year retrospective study. Lancet Diabetes Endocrinol 2014;2:396-405.

7. Morelli V, Reimondo G, Giordano R, Casa SD, Policola C, Palmieri S, et al. Long-term follow-up in adrenal incidentalomas: an Italian multicenter study. J Clin Endocrinol Metab 2014;99:827-34.

8. Debono M, Bradburn M, Bull M, Harrison B, Ross RJ, Newell-Price J. et al. Cortisol as a marker for increased mortality in patients with incidental adrenocortical adenomas. J Clin Endocrinol Metab 2014;99:4462-70.

9. Sbardella E, Minnetti M, D'Aluisio D, Rizza L, Di Giorgio MR, Vinci F, et al. Cardiovascular features of possible autonomous cortisol secretion in patients with adrenal incidentalomas. Eur J Endocrinol 2018;178:501-11.

10. Midorikawa S, Sanada H, Hashimoto S, Suzuki T, Watanabe $\mathrm{T}$. The improvement of insulin resistance in patients with adrenal incidentaloma by surgical resection. Clin Endocrinol (Oxf) 2001;54:797-804.

11. Erbil Y, Ademoğlu E, Ozbey N, Barbaros U, Yanik TB, Salmaslioğlu A, et al. Evaluation of the cardiovascular risk in patients with subclinical Cushing syndrome before and after surgery. World J Surg 2006;30:1665-71.

12. Colao A, Pivonello R, Spiezia S, Faggiano A, Ferone D, Filippella $\mathrm{M}$, et al. Persistence of increased cardiovascular risk in patients with cushing's disease after five years of successful cure. J Clin Endocrinol Metab 1999;84:2664-72.

13. Fassnacht M, Arlt W, Bancos I, Dralle H, Newell-Price J, Sahdev A, et al. Management of adrenal incidentalomas: European Society of Endocrinology Clinical Practice Guideline in collaboration with the European Network for the Study of Adrenal Tumors. Eur J Endocrinol 2016;175:G1-34.

14. Grumbach MM, Biller BKM, Braunstein GD, Campbell KK, Carney JA, Godley PA, et al. Management of the clinically inapparent adrenal mass ('incidentaloma'). Ann Intern Med 2003;138:424-9.

15. Mansmann G, Lau J, Balk E, Rothberg M, Miyachi Y, Bornstein SR. The clinically inapparent adrenal mass: update in diagnosis and management. Endocr Rev 2004;25:309-40.

16. Kloos RT, Gross MD, Francis IR., Korobkin M, Shapiro B. Incidentally discovered adrenal masses. Endocr Rev 1995;16:460-84.

17. Russi S, Blumenthal HT, Gray SH. Small adenomas of the adrenal cortex in hypertension and diabetes. Arch Intern Med 1945;76:284-91.

18. Nieman LK, Biller BMK, Findling JW, Newell-Price J, Savage, MO, Stewart PM, et al. The diagnosis of Cushing's syn- drome: an endocrine society clinical practice guideline. J Clin. Endocrinol Metab 2008;93:1526-40.

19. Bülow B, Jansson S, Juhlin C, Steen L, Thorén M, Wahrenberg $\mathrm{H}$, et al. Adrenal incidentaloma - Follow up results from a Swedish prospective study. Eur J Endocrinol 2006;154:419-23. 20. Libè R, Dall'Asta C, Barbetta L, Baccarelli A, Beck-Peccoz P, Ambrosi B, Long-term follow-up study of patients with adrenal incidentalomas. Eur J Endocrinol 2002;147:489-94.

21. Terzolo M, Pia A, Reimondo G. Subclinical Cushing's syndrome: definition and management. Clin Endocrinol 2012;76:128 .

22. Castro MA, Núñez SMA, Marazuela M. Autonomous cortisol secretion in adrenal incidentalomas. Endocrine 2019; 64:1-13.

23. Ruiz A, Michalopoulou T, Megia A, Näf S, Simón-Muela I, Solano E, et al. Accuracy of new recommendations for adrenal incidentalomas in the evaluation of excessive cortisol secretion and follow-up. Eur J Clin Invest 2019;49:e13048.

24. Bermejo AL, Aguado IH, Vera IJ, Recasens M, Esteve E, Casamitjana R, et al. Sex-specific, independent associations of insulin resistance with erythrocyte sedimentation rate in apparently healthy subjects. Thromb Haemost 2007;97:240-4.

25. Kuller L, Borhani N, Furberg C, Gardin J, Manolio T, O'Leary $\mathrm{D}$, et al. Prevalence of subclinical atherosclerosis and cardiovascular disease and association with risk factors in the cardiovascular health study. Am J Epidemiol 1994;139:1164-79.

26. Touboul PJ, Elbaz A, Koller C, Lucas C, Adraï V, Chédru F, et al. Common carotid artery intima-media thickness and brain infarction: The etude du profil genetique de l'infarctus cerebral (GENIC) case-control study. Circulation 2000;102:313-8.

27. O’Leary DH, Polak JF, Kronmal RA, Manolio TA, Burke GL, Wolfson SK Jr. Carotid-artery intima and media thickness as a risk factor for myocardial infarction and stroke in older adults. Cardiovascular Health Study Collaborative Research Group. N Engl J Med 1999;7;340:14-22.

28. Poredoš, P. Intima-media thickness: Indicator of cardiovascular risk and measure of the extent of atherosclerosis. Vasc Med 2004;9:46-54.

29. Touboul PJ, Hennerici MG, Meairs S, Adams H, Amarenco $\mathrm{P}$, Bornstein $\mathrm{N}$, et al. Mannheim carotid intima-media thickness consensus (2004-2006): An update on behalf of the advisory board of the 3rd and 4th Watching the Risk Symposium 13th and 15th European Stroke Conferences, Mannheim, Germany, 2004, and Brussels, Belgium, 2006. Cerebrovasc Dis 2007;23:75-80.

30. Evran M, Akkuş G, Bozdoğan İB, Gök M, Deniz A, Sert M, et al. Carotid intima-media thickness as the cardiometabolic risk indicator in patients with nonfunctional adrenal mass and metabolic syndrome screening. Med Sci Monit 2016;22:991-7.

31. Yener S, Genc S, Akinci B, Secil M, Demir T, Comlekci A, et al. Carotid intima media thickness is increased and associated with morning cortisol in subjects with non-functioning adrenal incidentaloma. Endocrine 2009;35:365-70.

32. Yener S, Baris M, Secil M, Akinci B, Comlekci A, Yesil S. Is there an association between non-functioning adrenal adenoma and endothelial dysfunction? J Endocrinol Invest 2011;34:26570 .

33. Ellis E, Chin PKL, Hunt PJ, Lunt H, Lewis JG, Soule SG. Is late-night salivary cortisol a better screening test for possible cor- 
tisol excess than standard screening tests in obese patients with Type 2 diabetes? N Z Med J 2012;125:47-58.

34. Mullan K, Black N, Thiraviaraj A, Bell PM, Burgess C, Hunter SJ, et al. Is there value in routine screening for Cushing's syndrome in patients with diabetes? J Clin Endocrinol Metab 2010;95:2262-5.

35. Gagliardi L, Chapman IM, Oloughlin P, Torpy DJ. Screening for subclinical cushing's syndrome in type 2 diabetes mellitus: low false-positive rates with nocturnal salivary cortisol. Horm Metab Res 2010;42:280-4.

36. Cansu GB, Atılgan S, Balcı MK, Sarı R, Özdem S, Altunbaş HA. Which type 2 diabetes mellitus patients should be screened for subclinical Cushing's syndrome? Hormones 2017;16:22-32. 